\title{
Overview of Zirconia: Application as Denture Base Material Substituting for Metal
}

\author{
Tomofumi Takano, Kaoru Sakurai
}

\begin{abstract}
Zirconia has recently been clinically applied as an ideal tooth color material which acquires superior mechanical properties with high stability without water absorption and dissolution with the progression of the CAD/CAM technique. Dental prosthetic materials have recently evolved to those for metal-free restoration because of the strength, esthetics and environmental protection concerning rare metals. In addition, the increase in demands for metal-free restoration is not limited to fixed prosthesis and dental implants, and it is also directed to application for removable prosthesis. The load-bearing ability of zirconia has been shown to be comparable to that of $\mathrm{Co}-\mathrm{Cr}$ alloy. Ce-TZP/Al $\mathrm{O}_{3}$ nanocomposite (NANOZR) with strength, toughness, and thermal stability comparable or superior to those of previously used yttria-stabilized zirconia (Y-TZP) has been clinically applied, suggesting its applicability as a denture base material substituting for metal.
\end{abstract}

Keywords: Metal-free restoration, Zirconia, Ce-TZP/AI ${ }_{2} \mathrm{O}_{3}$ nanocomposited, Removable prosthesis.

How to cite this article: Takano T, Sakurai K. Overview of Zirconia: Application as Denture Base Material Substituting for Metal. Int J Prosthodont Restor Dent 2013;3(4):153-156.

Source of support: Nil

Conflict of interest: None

\section{INTRODUCTION}

\section{Reason why Metal-Free Restoration Attracts Attention}

Biomaterials for dental use are classified into metal, ceramics, synthetic polymer and composite materials of these. For dental prosthesis, previous ceramics and resin were brittle, and the use of these alone for restoration and dental prosthesis preparation was limited due to the problem of the materials' strength. Thus, metal has been frequently used; prioritizing mechanical strength over esthetics, but demands for metal-free restoration has recently increased due to esthetic problems of metal color penetration through the marginal gingiva and gingival staining by metal, a problem of metal allergy, and environmental protection concerning rare metals.

Materials used for metal-free restoration include resin and ceramics. Resin is disadvantageous in that water absorption, staining and plaque adhesion occur in the material with long-term use. ${ }^{1}$ The advantages of ceramics are biocompatibility and esthetics associated with their superior chemical stability. Ceramics have been used for fixed prosthesis as a biocompatible material, but fixed prosthesis have not been prepared with ceramics alone because of the problem of strength: tensile and impact strengths of previous ceramics were weaker than those of metals. However, with the progression of CAD/CAM techniques, all-ceramic restoration systems applying high-strength ceramics, represented by zirconia, were put on the market one after another in the 2000s as ideal tooth color materials with high stability and superior mechanical properties without water absorption and dissolution. $^{2}$

\section{Reason why Zirconia Attracts Attention among Ceramics}

Feldspathic porcelain has been used for porcelain-fused metal restoration and dispersion-strengthening glass ceramics, glass-infiltration aluminum ceramics, and highdensity sintered aluminum ceramics, have been used. Since high-density sintered aluminum ceramics are very strong, they were applicable for the restoration of allceramic crowns and 3 units of fixed prosthesis for a single anterior tooth replacement, but there has been no metal-free restoration material strong enough to apply for long-span fixed prosthesis for molar regions. Accordingly, attention was paid to zirconia which has a higher strength than previous metal-free restoration materials. ${ }^{3-5}$

Phase transformation occurs in the crystal structure of zirconia depending on the temperature: monoclinic at room temperature, tetragonal at $1,170^{\circ} \mathrm{C}$, and cubic at $2,370^{\circ} \mathrm{C}$. When rare earth oxides (yttria and ceria) are dissolved in zirconia, oxygen vacancies are formed in the crystal structure, and the material becomes tetragonal and cubic in a stable or metastable state even at a room temperature, through which destruction by temperature changes can be inhibited. This oxide-added zirconia is termed stabilized or partially stabilized zirconia. ${ }^{6}$

Zirconia, which is stronger than previously used ceramics and superior in biocompatibility, has rapidly become widely used an all-ceramic restorative material in dentistry. One reason is its greatly superior flexure strength and fracture toughness among many types of ceramic. ${ }^{7,8}$ Zirconia is greatly superior in flexure strength compared to other high-strength ceramics for dental use (glass ceramics and alumina), and it can be safely used as a material for longspan fixed prosthesis. 
When an external force is loaded on a material and induces cracking, resistance to cracking is termed fracture toughness. The fracture toughness value of zirconia is greater than those of general feldspathic porcelain used for porcelain fused to a metal restoration, leucite-strengthening glass ceramics, and high-density sintered aluminum ceramics. Regarding the reason for the high toughness of zirconia, it is considered that, when cracking causing destruction occurs, stress-induced transformation of the crystal structure from tetragonal to monoclinic phase occurs in the cracked region, ${ }^{9}$ with which $4 \%$ volume expansion occurs, and this disturbs the progression of cracking ${ }^{9}$ (stress-induced transformation toughening).

The current zirconia for dental use is combined with yttria. Yttria-partially stabilized tetragonal zirconia (Y-TZP), in which the crystal structure is stabilized in the tetragonal state at room temperature, is frequently used, and its fracture toughness is the highest among ceramic materials. ${ }^{6,10}$ However, although Y-TZP shows the general chemical durability of ceramics, it is known to undergo low-temperature degradation (LTD) in the aqueous solutions encountered in the oral environment because the surface crystal structure transforms from the tetragonal to monoclinic state under a hydrothermal condition, ${ }^{11}$ and this phase transformation is considered to be a cause of strength reduction in the oral cavity.

While, Panasonic Corporation of Japan presented NANOZR, a composite material comprised of zirconia and alumina using ceria as a stabilizing material, and acquired pharmaceutical approval in October 2006. In this material, alumina particles with a size of several hundreds of $\mathrm{nm}$ incorporated into ceria-stabilized zirconia crystals, fine ceria-stabilized zirconia particles with a size of several tens of nm incorporated into other alumina crystals, and these tissues are combined to form a composite. Residual stress is produced between each crystal grain, resulting in a higher strength than those of simple alumina and Y-TZP.

It has been reported that the strength of Y-TZP is reduced by LTD ${ }^{12}$ as described above, but such strength reduction did not occur in another report. ${ }^{13}$ However, the concern for long-term durability has not been solved, and a question concerning the long-term stability of Y-TZP remains. In contrast, the durability of NANOZR against low-temperature degradation has been confirmed. ${ }^{8}$

Regarding the characteristics of NANOZR, superior toughness and comparable strength to those of Y-TZP on evaluation using the IF method (standard fracture toughness test method) have been reported. ${ }^{14}$

\section{Possibility of using NANOZR as a Denture Base Material}

Since NANOZR has a marked mechanical strength, and long-term stability in the mouth can be expected, clinical application for fixed prosthesis and dental implants has been progressing. ${ }^{3,4,15} \mathrm{We}$ also reported that NANOZR has mechanical properties applicable for the fixture of dental implants. ${ }^{16}$

As described above, dental prosthetic materials have recently evolved to those for metal-free restoration because of the strength, esthetics and environmental protection concerning rare metals. In addition, the increase in demands for metal-free restoration is not limited to fixed prosthesis and dental implants, and it is also directed to application for removable prosthesis. The load-bearing ability of Y-TZP has been shown to be equivalent to that of Co-Cr alloy, ${ }^{17}$ and NANOZR may also be applicable for denture base material substituting for metal because its mechanical strength is greater than that of Y-TZP.

\section{DISCUSSION}

Properties required for denture base materials include the absence of deformation as a force-transmitting substance, for which metals, such as Co-Cr and gold alloys, have been frequently used.

Requirements of denture base materials include the following conditions:

1. Resistance to occlusal pressure, superior abrasion resistance and the absence of plastic deformation.

2. Simple molding and repair.

3. Low specific gravity and high thermoconductivity.

4. Insoluble with saliva, food, and drink, tasteless, odorless, and not stimulating the oral mucosa.

5. No discoloration in the mouth.

6. Not adhered to by food and cleaning is easy.

7. Freely stainable.

An existing denture base material, acrylic resin, is inferior to metal with regard to water absorption and strength. Polyamide and polyester resins called nonclasp denture, show only low-level water absorption, but, regarding the mechanical properties, these have a problem with stiffness as a denture base material. On the other hand, metal-base dentures have an overall shape similar to that of resinbase dentures, and metal is partially used in the denture base. Since the metal base does not absorb water and has a sufficient strength, the thickness can be reduced to $1 / 2-1 / 3$ of that of resin bases. Metals used for the framework include gold and Co-Cr alloys, pure titanium and titanium alloy. Allergy may be induced depending on the metal used. Ti alloy-induced allergy has recently been reported. ${ }^{18}$ 
Advantages of metal bases compared to resin bases are as follows:

- The strength is high, and fracture is unlikely to occur even when the base is thinned.

- No water absorption and less plaque adhesion.

- Thermoconductivity is high and readily transmits thermal sensation to the mucosa, improving the sense of taste.

- Superior fitting and good feeling of attachment On the other hand, metal bases have the following disadvantages:

- Adjustment of denture bases is difficult.

- Reline is possible, but reline of a metal base using metaladhesive resin loses the advantages of the metal-base denture.

- Metal allergy may be induced depending on the metal used.

- The prosthetic procedure is complex.

- The medical expense is high.

It may be improvable by using NANOZR as a denture base material instead of metal base about the complicatedness of allergy to metal and artisan operation in the above disadvantages. Preparation of a metal base by casting is complex, and there is concern over the homogeneity of products due to casting defects. In contrast, NANOZR denture bases are prepared using CAD/CAM,

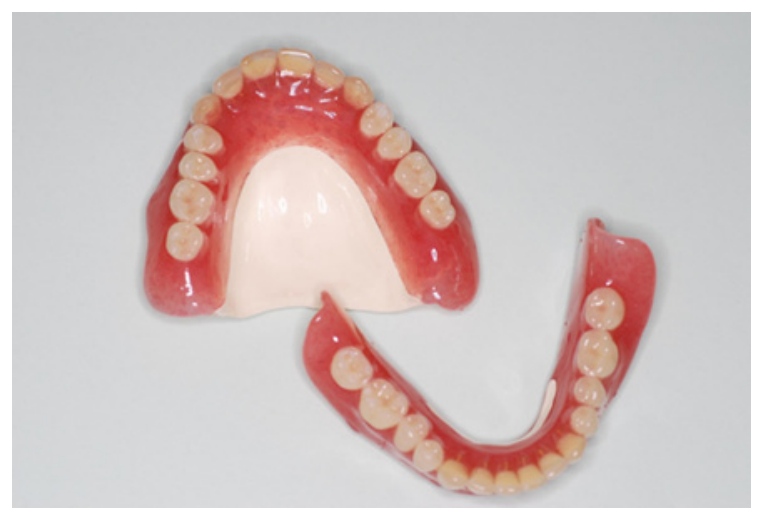

Fig. 1: Upper and lower complete dentures using NANOZR as a denture base material substituting for metal

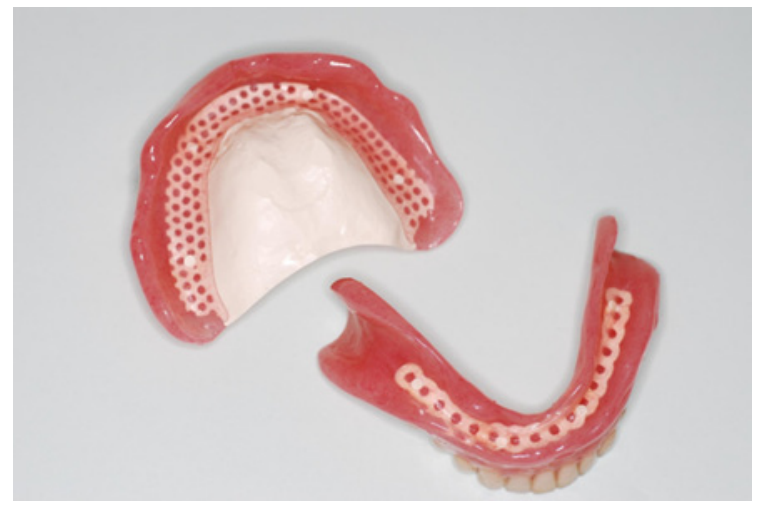

Fig. 2: These denture bases were prepared using CAD/CAM technique which simplifies the prosthetic procedure and eliminates concern over casting defects because the denture base is prepared by shaving a block. Since a high plaque adhesioninhibitory effect of Y-TZP has been reported, ${ }^{19}$ this effect may also be expected for NANOZR denture bases.

When a metal base is used for the oral cavity in which a metal restoration is already present, the addition of dissimilar metal may induce a galvanic current, or a metallic taste may be sensed, ${ }^{20}$ whereas there is no concern regarding a metallic taste for NANOZR because it is a ceramic and no elution occurs, although it has a mechanical strength comparable to metal as a denture base material. It is also superior with regard to the protection of rare metals. Based on the above, we introduced NANOZR into actual clinical practice in 2012 (Figs 1 to 4 ). The crown thickness using NANOZR can be thinned down to $0.3 \mathrm{~mm}$, but we limit the NANOZR base thickness to $1.0 \mathrm{~mm}$.

Also about the charge of zirconia base, since it is manufacture at cost comparable as titanium base, zirconia base can be set to one of the clinical choices.

Another concern with zirconia-base dentures is adhesiveness to acrylic resin. Stress is continuously added to the finish line of zirconia and acrylic resin. Therefore, it is necessary to investigate adhesiveness to acrylic resin for long-term clinical application of zirconia-base dentures. It

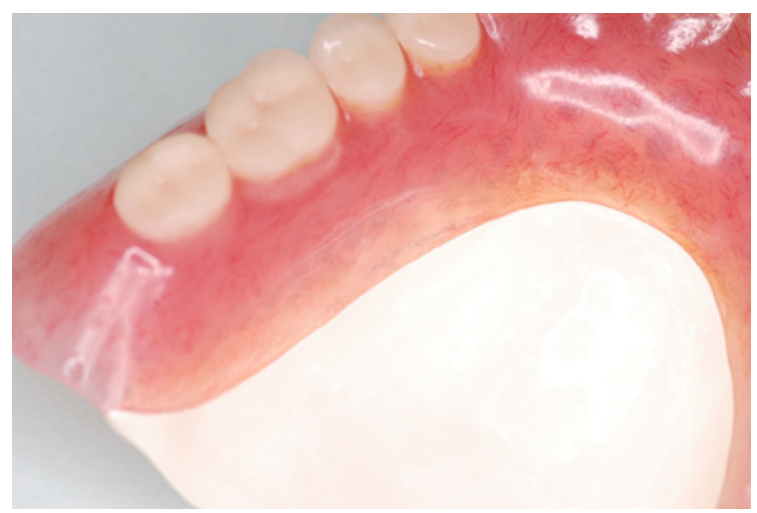

Fig. 3: 10 months later after denture insertion. There are no blot at the finish line

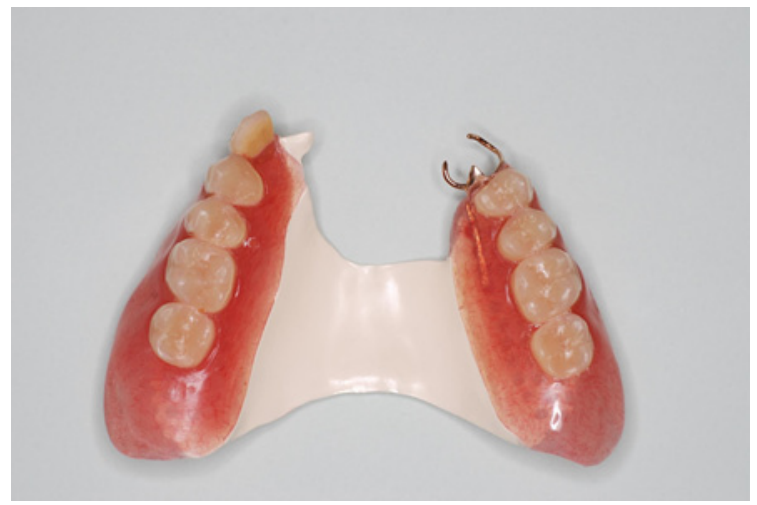

Fig. 4: Palatal plate is made by NANOZR. Retainers are using wright wire clasp and precision attachment 
may also be necessary to investigate the oral sensation with zirconia-base dentures with regard to sensory improvement, which is an advantage of metal bases.

\section{CONCLUSION}

Zirconia has sufficient properties as a restoration material substituting for metal, and its advantages are more than just supplementing restoration with metal (no metal color, less adhered to by plaque, no casting defect, and protection of rare metals). Zirconia is a material expected to be applied for not only crown prosthetics but also denture bases.

\section{REFERENCES}

1. Radford DR, Challacombe SJ, Walter JD. Denture plaque and adherence of Candida albicans to denture-base materials in vivo and in vitro. Crit Rev Oral Biol Med 1999;10(1):99-116.

2. Miyazaki T, Nakamura T, Matsumura H, Ban S, Kobayashi T. Current status of zirconia restoration. J Prosthodont Res 2013;57(4):236-261.

3. Andreiotelli M, Wenz HJ, Kohal RJ. Are ceramic implants a viable alternative to titanium implants? A systematic literature review. Clin Oral Implants Res 2009;20 Suppl 4:32-47.

4. Karakoca S, Yilmaz H. Influence of surface treatments on surface roughness, phase transformation and biaxial flexural strength of Y-TZP ceramics. J Biomed Mater Res B Appl Biomater 2009;91(2):930-937.

5. Sato H, Yamada K, Pezzotti G, Nawa M, Ban S. Mechanical properties of dental zirconia ceramics changed with sandblasting and heat treatment. Dent Mater J 2008;27(3):408-414.

6. Piconi C, Maccauro G. Zirconia as a ceramic biomaterial. Biomaterials 1999;20(1):1-25.

7. Ban S. Reliability and properties of core materials for allceramic dental restorations. Japanese Dental Science Review 2008;44(1):3-21.

8. Tanaka K, Tamura J, Kawanabe K, Nawa M, Oka M, Uchida M, et al. $\mathrm{Ce}-\mathrm{TZP} / \mathrm{Al}_{2} \mathrm{O}_{3}$ nanocomposite as a bearing material in total joint replacement. J Biomed Mater Res 2002;63(3): 262-270.

9. Swain MV. Grinding-induced tempering of ceramics containing metastable tetragonal zirconia. Journal of Materials Science 1980;15(6):1577-1579.

10. Garvie RC, Nicholson PS. Phase analysis in zirconia systems. Journal of the American Ceramic Society 1972;55(6): 303-305.
11. Hirano M. Inhibition of Low Temperature Degradation of Tetragonal Zirconia Ceramics: a review. British Ceramic Transactins and Journal 1992;91(5):139-147.

12. Pittayachawan P, McDonald A, Young A, Knowles JC. Flexural strength, fatigue life and stress-induced phase transformation study of Y-TZP dental ceramic. J Biomed Mater Res B Appl Biomater 2009;88(2):366-377.

13. Kosmac T, Oblak C, Jevnikar P, Funduk N, Marion L. Strength and reliability of surface treated Y-TZP dental ceramics. J Biomed Mater Res 2000;53(4):304-313.

14. Nawa M, Nakamoto S, Sekino T, Niihara K. Tough and strong Ce-TZP/Alumina nanocomposites doped with titania. Ceramics International 1998;24(7):497-506.

15. Nakazato T, Takahashi H, Yamamoto M, Nishimura F, Kurosaki N. Effect of polishing on cyclic fatigue strength of CAD/CAM ceramics. Dent Mater J 1999;18(4):395-402.

16. Takano T, Tasaka A, Yoshinari M, Sakurai K. Fatigue strength of Ce-TZP $/ \mathrm{Al}_{2} \mathrm{O}_{3}$ nanocomposite with different surfaces. J Dent Res 2012;91(8):800-804.

17. Sanaoka S, Goto T, Watanabe K, Higashino Y. Application of dental zirconia to major connector. J. Gifu Dent Soc 2010;37(1):41-46.

18. Javed F, Al-Hezaimi K, Almas K, Romanos GE. Is titanium sensitivity associated with allergic reactions in patients with dental implants? A systematic review. Clin Implant Dent Relat Res 2013;15(1):47-52.

19. Scarano A, Piattelli M, Caputi S, Favero GA, Piattelli A. Bacterial adhesion on commercially pure titanium and zirconium oxide disks: an in vivo human study. J Periodontol 2004;75(2): 292-296.

20. Morris HF. Veterans Administration Cooperative Studies Project No. 147: association of metallic taste with metal ceramic alloys. J Prosthet Dent 1990;63(2):124-129.

\section{ABOUT THE AUTHORS}

\section{Tomofumi Takano}

Assistant Professor, Department of Removable Prosthodontics and Gerodontology, Tokyo Dental College, Chiba, Japan

CorrespondenceAddress: 1-2-2, Masago, Mihama-ku, Chiba 261-8502 Japan, Phone: +81-432703933, Fax: +81432703935, e-mail: takanotomofumi@tdc.ac.jp

\section{Kaoru Sakurai}

Professor and Chair, Department of Removable Prosthodontics and Gerodontology, Tokyo Dental College, Chiba, Japan 